\title{
Performance Measures in the Management of Chronic Obstructive Pulmonary Disease in Primary Care - A Retrospective Analysis
}

Kaufmann, Carla ; Markun, Stefan ; Hasler, Susann ; Dalla Lana, Kaba ; Rosemann, Thomas ; Senn, Oliver ; Steurer-Stey, Claudia

DOI: https://doi.org/10.1024/1661-8157/a002101

Posted at the Zurich Open Repository and Archive, University of Zurich ZORA URL: https://doi.org/10.5167/uzh-112544

Journal Article

Originally published at:

Kaufmann, Carla; Markun, Stefan; Hasler, Susann; Dalla Lana, Kaba; Rosemann, Thomas; Senn, Oliver; SteurerStey, Claudia (2015). Performance Measures in the Management of Chronic Obstructive Pulmonary Disease in Primary Care - A Retrospective Analysis. Praxis, 104(17):897-907.

DOI: https://doi.org/10.1024/1661-8157/a002101 
Performance measures in the management of chronic obstructive pulmonary disease in primary care - A retrospective analysis

Carla Kaufmann ${ }^{1}, \mathrm{MD}$; Stefan Markun ${ }^{1}, \mathrm{MD}$; Susann Hasler ${ }^{1}, \mathrm{MD}$; Kaba Dalla Lana ${ }^{1}$, PRT; Thomas Rosemann ${ }^{1}$, MD, PhD; Oliver Senn ${ }^{1}$, MD; Claudia Steurer-Stey ${ }^{1 *}$, MD

${ }^{1}$ Institute of Primary Care, University of Zurich

email addresses

Corresponding author *

Claudia Steurer-Stey*_claudia.stey@usz.ch

Carla Kaufmann: ca.kaufmann@bluemail.ch

Stefan Markun: Stefan.markun@usz.ch

Susann Hasler: $\quad$ susann.hasler@usz.ch

Kaba Dalla Lana: $\quad$ kaba.dallalana@usz.ch

Thomas Rosemann: $\quad$ thomas.rosemann@usz.ch

Oliver Senn: $\quad$ oliver.senn@usz.ch

Institute of Primary Care, University of Zurich

Pestalozzistrasse 24

8091 Zurich

Switzerland

Phone: +41442552662

Fax: +41442559097

Running titel: COPD and performance measures

Key words: Performance, measures, COPD, quality, primary care, retrospective 


\section{Introduction}

The prevalence of chronic obstructive pulmonary disease (COPD) in Switzerland is approximately $10 \%$, comparable to other European countries $(1,2)$. COPD is associated with high morbidity, increased mortality and enormous economic costs $(1,4)$. COPD has therefore became a focus of the "QualiCCare" project, initiated by the Swiss Federal Department of Home Affairs (FDHA) in 2011 with the aim to improve quality in chronic disease care on a national level. The driving force behind "QualiCCare" was the mounting evidence that patients with chronic health conditions do not receive recommended care despite existing clinical practice guidelines(5). This is a problem in particular for patients with COPD, who receive recommended treatment only during $50 \%$ of encounters with providers(6-8).

Studies from various countries have shown that successful COPD care with improved quality of life and reduced use of health care resources is based on appropriate pharmacological treatment, planned regular visits, patient education, adequate exacerbation management and collaborative, integrated disease management $(9,10),(11)$. Guidelines address management of stable COPD as well as exacerbations and give recommendations for evidence based care $(5,12)$. However, variations in treatment and non-adherence to recommendations have a negative impact on the quality of care $(8,13-15)$. The Institute of Medicine (IOM) quality report emphasizes the need for better assessment of care quality by measuring performance (16).

Primary care is pivotal in this respect (17-20) as providers can transfer recommendations and implement them into daily practice, prompting quality improvements in care delivery (16, 21). Therefore, the aim of the present study was to investigate the documentation of COPD PMs in primary care practices of the Canton Zurich in Switzerland, based on guideline recommendations $(5,12)$.

\section{Methods}

The study was part of the improving CARe in Obstructive Lung disease (CAROL) project. CAROL is a cluster-randomized controlled trial that aims to assess whether GP and primary care team participation in the COPD quality improvement intervention ("QualiCCare") improves adherence to recommended care elements and processes and which evaluates the impact on COPD care. A detailed research protocol has been published elsewhere(22).The CAROL study (ClinicalTrials.gov: NCT01921556) was approved by the ethics committee of the Kanton Zurich (Ref. KEK-ZH_Nr, 2013-0189). Protection of privacy of both patients and the participating practices was ensured.

For this study a multi-site retrospective design was chosen analyzing the medical records of 14 different primary care practices in the canton of Zurich, with a focus on the two major regions "Winterthur" and "Zurich", which care for both urban and rural populations. 


\section{Setting and participating practices}

The participating practices were recruited from 30 practices (single and group practices) in the canton of Zurich who agreed to participate in the CAROL project. Five practices were located in the area of Winterthur. Winterthur is the second largest city in the canton with about $105^{\prime} 000$ inhabitants. Zurich is the largest city with around 390'000 inhabitants. Its agglomeration is home to around 1.19 million people.

Nine practices were from the area of Zurich. One of the Zurich practices runs the validated "Living well with COPD" (LWWCOPD) program(9) since 2010. The LWWCOPD program is based on the Chronic Care Model(23)and can be applied to a variety of chronic illnesses and health care settings (24). Key elements of the LWWCOPD program are a practice team with defined roles, evidence-based practice incorporating guideline recommendations, patient education and self-management support as well as regular follow up and coordination of care(25).

\section{Patient enrolment}

Each participating GP reported patients with physician diagnosed COPD and regular outpatient visits in 2012. The selection criteria required that patients had a physician diagnosed COPD and had seen the GP at least three times in 2012, regardless of the reason for the consultation. Patients were excluded if they died before the end of 2012 .

\section{Data collection and analysis}

Data collection comprised a 12-month retrospective medical chart review. Demographic and clinical characteristics were assessed.

We analyzed the documentation of COPD performance status by searching the medical notes for the following relevant measures. 1. Assessment of smoking status with smoking cessation advice and smoking cessation intervention; 2 . Influenza vaccination; 3. Assessment and advice for physical activity; 4. Appropriate pharmacological treatment; 5. Instruction of correct inhalation technique; 6. Information about disease; 7. Instruction in exacerbation management and availability of a written action plan; 8. Advice or referral to pulmonary rehabilitation and 9 . Proactive and integrated services indicating collaboration and networking with specialists, secondary and hospital tertiary care services as well as with other health care deliverers and community resources.

An independent and trained research assistant reviewed each patients medical records using a carefully developed checklist including the above specified performance measures (PM). Several data sources were studied, e.g. entries in the medical records, referral letters and invoice coding to ensure comprehensive data collection. 
In order to assess the severity of COPD spirometry results from the time of diagnosis and follow-up measurements from 2012 were included in the data analysis. The majority (91/115) of the medical records were computer based, 24 were paper based.

\section{Outcome measures}

For each patient the number of documented performance indicators was calculated. A composite score was established and noted.A Score of 1: denoted the documentation of 0-2 PMs, a Score of 2 the documentation of 3-5 PMs, a Score of 3: the documentation of 6-8 PMs and a Score of 4:the documentation of all nine PMs.

These results were compared to the practice running the validated LWWCOPD program (practice B).

\section{Statistical analysis}

Patient characteristics and documented PMs are presented as means (range) and percentages for the total population and stratified according to the regions Zurich and Winterthur as well as the practice running the COPD program (practice B). Group comparisons of patient characteristics and PMs were performed by unpaired t-tests and chisquared statistics as appropriate. Fisher exact test was used for small sample sizes $(n<5)$.

\section{Results}

\section{Practices characteristics}

Data from 14 primary care practices ( 7 single, 7 group practices) were evaluated. Five of the practices were located in the region of "Winterthur" and nine in the "Zurich" region. Data from 115 patients (37 in Winterthur, 78 in Zurich) were available; the majority of the patient data were collected in group practices (83\%) and from computer based $(79 \%)$ medical records (table 1). The group practice in Zurich running the "Living well with LWWCOPD program(9) (practice B) contributed 20 computer based medical records to this study (table 1).

\section{Patient characteristics}

Data from 115 patients (57\% male) with a mean age of 68 years (range 44-93) were analyzed (table 2). Most baseline characteristics of the patients showed no significant difference between the practices without a COPD program (Total-B) and the practice in Zurich with the COPD program (B). Patients from practice $B$ were more likely to be active smokers, had received a diagnosis of COPD more recently and were subjected to significantly more spirometries in 2012.

In general, no big difference in patient characteristics existed between the COPD patients from the rural (Winterthur) and the urban (Zurich) population in our study. COPD patients from Winterthur had been diagnosed with COPD for a significantly shorter amount of time 
than those in Zurich (table 2). The burden of comorbidities was high with documentation of one or more comorbidities in $73 \%$ of patients. The most frequently documented comorbidities were hypertension (57\%), followed by coronary heart disease $(28 \%)$, depression $(23 \%)$, diabetes (15\%) and heart failure (9\%). However, heart failure and diabetes were not documented in the twenty patients from practice $B$.

Spirometric confirmation of COPD was documented in $83 \%$, either at the time of diagnosis or during follow up in 2012. The year of COPD diagnosis was documented in 94 of the 115 patients (82\%) and ranged between 1997 and 2012; on average COPD diagnosis was established 5.28 years before the current data collection.

At the time of diagnosis, GOLD classification (12) was documented in 80 patients (70\%). Of these $11 \%$ were classified as GOLD I, $64 \%$ as GOLD II , $21 \%$ as GOLD III and $4 \%$ as GOLD IV. GOLD classification in 2012 was documented in 87 of the 115 patients (76\%) with $8 \%$ of COPD patients classified as GOLD I, $51 \%$ as GOLD II, $23 \%$ as GOLD III and $9 \%$ as GOLD IV.

Documentation of at least one of the main clinical symptoms of COPD (cough, sputum, and/or dyspnea) was found in $83 \%$ of the medical records. Dyspnea was the most frequently documented symptom in $68 \%$, followed by cough in $54 \%$ and sputum production in $35 \%$ of patients.

In half (53\%) of the patient records exacerbations could be tracked with an average of 1.4 exacerbations/year and $\geq 2$ exacerbations within 12 months in $16 \%$ of patients. On average 1.24 hospitalizations per year because of COPD were necessary (table 2).

\section{Documentation of performance measures}

Table 3 and figure 1 show the documentation of non-pharmacological PMs.

\section{Smoking status and smoking cessation counseling:}

In total smoking status was documented in $95 \%$ of the patients. Fifty patients (46\%) were current smokers. Pack years (py) were documented in $77 \%$ with an average of 56 py (range: 22-150 pack years). In $74 \%$ of the current smokers smoking cessation advice was given and a stop smoking program initiated in $52 \% .70 \%$ of the current smokers were documented as being motivated to cease smoking, $34 \%$ were not.

Practices without a COPD program $($ Total $-B=A)$ vs. the practice with $L W W C O P D$ program $(B)$ The percentage of documented smoking cessation advice offered in active smokers was $65 \%$ in practices $A$, and $100 \%$ in practice $B$. A smoking cessation program was initiated in $38 \%$ of the smokers in practices $A$ and in $92 \%$ of smokers in practice $B$, a significantly higher percentage $(p<0.01)$.

\section{Influenza vaccination:}


Overall, half of the patients received an influenza vaccination/recommendation in 2012 without any statistical difference between the regions or between $A(49 \%)$ and $B(45 \%)$.

\section{Physical activity and pulmonary rehabilitation:}

In $60 \%$ of all patient records assessment of physical activity and in $53 \%$ motivation and advice for physical activity was detailed.

Practices without COPD program $(A)$ vs. practice with $L W W C O P D$ program $(B)$

In practices $A$ assessment of physical activity was documented in $52 \%$ of patients compared to $95 \%$ of patients in $\mathrm{B}$. All patients in practice $\mathrm{B}$ were given advice regarding pulmonary rehabilitation compared to eleven (12\%) in A. In $85 \%$ of patients in practice $B$ a referral to a pulmonary rehabilitation program was traceable compared to $12 \%$ of patients in the $A$ practices. These differences were highly significant $(p<0.01)$.

\section{Information about COPD, information about therapy and instruction in correct inhalation technique:}

These three quality indicators were documented in $45 \%$ to $48 \%$ of patients in practices $\mathrm{A}$ compared to $95 \%$ in practice $\mathrm{B}$ (the practice running the $\angle W W C O P D$ program), denoting a significant difference $(p<0.01)$.

\section{Exacerbation management and written action plan:}

Instructions regarding exacerbation management were traced in only $24 \%$ of patients records and an action plan recorded in only $16 \%$ of patients.

Practices without COPD program $(A)$ vs. practice with $L W W C O P D$ program $(B)$

Analysis of patients charts from A showed scant documentation of instructions regarding exacerbation management $(8 \%)$ or the existence of an action plan $(2 \%)$, with no regional difference between Zurich and Winterthur. Instructions for exacerbation management were documented in all patient notes from practice $B$ and $80 \%$ additionally had a clear action plan recorded $(p<0.01)$.

\section{Proactive follow up and integrated services for patient care:}

For $60 \%$ of all COPD patients integrated care was documented. Contact with pneumologists was registered in $57 \%$, with hospitals in $39 \%$, physiotherapists in $32 \%$ and community support services in $15 \%$. In about half of all medical records, a proactive follow up of COPD patients was documented.

Practices without COPD program $(A)$ vs. practice with $L W W C O P D$ program $(B)$ In practices $A$ integrated care was documented in $53 \%$ compared to $95 \%$ of patients in practice $B(p<0.01)$. Collaboration with a specialist was documented in $40 \%$ of COPD 
patients from A compared to $95 \%$ of patients from B. Proactive care and regular follow up was significantly more frequent in B $(95 \%)$ compared to $A(42 \%)(p<0.01)$.

\section{Pharmacological treatment:}

Table 4 summarizes the COPD treatment regimes prescribed. The mean number of documented COPD medications was 2.09 (range: 0-6 drugs) without any significant difference between settings $A$ and $B$ or between the regions of Zurich and Winterthur. 80 of 115 patients $(70 \%)$ were treated with inhaled corticosteroids (ICS), 70 of 80 patients $(61 \%)$ in combination with a long-acting beta2-agonist (LABA). With respect to the disease severity recorded (32\% GOLD III or GOLD IV documented in 2012) and the frequency of exacerbations (16\%) this reflects overtreatment. Patients with severe COPD and patients with frequent exacerbations received adequate treatment with ICS $(86 \%$ and $81 \%$ respectively) .

Eighty-one out of 115 (70\%) patients were prescribed a long-acting antimuscarine antagonist (LAMA). Long-acting beta2-agonist (LABA) treatment was documented in $22 \%$.

Short acting beta2-agonists (SABA) were prescribed in 36\% of the COPD patients, whereas none of the patients inhaled a short acting antimuscarine antagonist (SAMA). Only 6 out of 115 patients (5\%) were prescribed a combination of a short-acting beta2-agonist and a shortacting antimuscarine antagonist (SABA/SAMA). In Winterthur significantly fewer patients were given an ICS/LABA combination therapy (43\%) compared to the Zurich practices. This was true both for those practices with and those without a COPD program (70\% versus $69 \%$ respectively). In Winterthur significantly more patients were prescribed LAMA (84\%), compared to the Zurich practices without the $L W W C O P D$ program (59\%). LAMA treatment was prescribed to $80 \%$ of patients in the practice implementing the $\angle W W C O P D$ program Treatment with LABA was documented in $32 \%$ of patients in Winterthur, and in $16 \%$ and $20 \%$ of the patients in the Zurich practices with and without the LWWCOPD program, showing no statistical difference (table 4).

\section{Composite score of documented performance measures:}

Overall all practices had low scores of 1 or 2 (in $60 \%$ of patients). A score of 1 (0-2 PMs documented) was found in $23 \%$, a score of 2 (3-5 PMs) in $37 \%$ of patients. A score of 3 (6-8 PMs) could be established in $34 \%$ and the maxium score of 4 (with all nine PMs documented) in only $7 \%$ of the 115 medical records.

Comparison with B showed that significantly higher scores of 3-4 in $95 \%$ of patients were achieved compared to $29 \%$ in A.

\section{Discussion}

Main findings 
This is the first evaluation of the documentation of COPD PMs in a primary care setting in Switzerland. Our data demonstrate a documentation gap in relation to recommended care and a wide variation between practices regarding documentation of COPD PMs. A significantly better documentation of COPD PMs was achieved with the implementation of a validated COPD program(26).

\section{Strength and limitations}

COPD represents an important condition in which improvement of care would in all likelihood have a high impact.. A strength of our study was that the assessed measures were validated to demonstrate effects on clinically important patient outcomes. We did not rely on questionnaires sent to the GPs, but had patient records and data gathering systems systematically reviewed by an independent research assistant, thus ensuring comprehensive data collection.

Limitations of this study include the low sample size, documentation bias and generalisability of the results. The participation of practices and GPs that were part of the CAROL study, a prospective RCT, represent a selected and probably more motivated GP population. However, the latter would likely have biased the data toward an underestimation of the documentation gap. Small samples are more prone to the play of chance which means that the significant effects which are observed in this study may be skewed. In the practice implementing a COPD program a chest physician and a respiratory physiotherapist were part of the team and oversaw the LWWCOPD program. Referrals and coordination of care were therefore more easily accomplished. This redesign of care using an inhouse care team approach is not common in Swiss primary care. In addition, the quality of documentation was assessed in the canton of Zurich and cannot be generalized to Switzerland as a whole or other countries and health care systems.

Finally, yet importantly, missing documentation is not synonymous with poor performance. Some PMs may have been implemented but not documented by the GPs. It is also likely that in patients referred to specialists the PMs were documented but not explicitely mentioned in reports sent to the GPs. It is difficult to conclude from our data how wide the gap between current and ideal COPD practice is and how this gap varies across different organizations.

Interpretation of findings in relation to previously published work

Two thirds of patients in our study received smoking cessation advice, but only around half received recommendations regarding influenza vaccination.

Smoking cessation is the only intervention that slows the rate of lung function decline and improves survival in COPD patients $(27,28)$. The documented counselling rate in the present study is much better than the $50 \%$ reported from former Swiss primary care data and is more in line with international benchmarks $(8,13)$. 
Influenza vaccination prevents acute exacerbations of COPD and reduces the rate of hospitalization by about 40\%-50\%(29). The low documented influenza vaccination percentage (only half of the COPD patients) therefore reflects a substantial deficit with negative implications for patients and the health care system. This could be changed by implementing reminder and recall interventions, as shown in data from other countries (30). Our data also indicate that only a minority of COPD patients in primary care are offered pulmonary rehabilitation advice or a referral for pulmonary rehabilitation, in line with data from other countries(13). The remarkably low documentation of self-management support and exacerbation-management or instruction with a written action plan is striking. Pulmonary rehabilitation and self-management education are effective ways of lessening the impact of COPD burden on patients and the health system by preventing exacerbations and hospital admissions as well as readmissions $(9,31)$. In half of the patient records documentation of exacerbations wasfound. The percentage of frequent exacerbations (16\% of patients) and an average of 1.24 hospitalizations per year because of COPD exacerbations suggest that the awareness for these as the main drivers of morbidity and cost has to be increased and that rehabilitation and self-management education need to be proclaimed as effective preventive actions, in analogy to programs established for heart disease(32). A recently published report by Australian GPs identified an awareness barrier, insufficient knowledge of how to refer for pulmonary rehabilitation, anticipated access difficulties for patients and cost benefit issues as major problems (33).

Spirometric confirmation of COPD with a remarkably high documentation of GOLD grading according to guidelines(5) revealed that the majority of evaluated COPD patients have mild to moderate COPD. A lasting hot topic in COPD management is pharmacological overtreatment with ICS in patients with mild to moderate disease, as confirmed in our study $(5,12)$. While overtreatment with ICS was common, undertreatment in those with severe disease or frequent exacerbations was less frequent.

With respect to effective treatment a correct inhalation technique is of central importance and depends on the correct use of the inhalation device. Instruction of inhalation technique was performed significantly more often in the practice with the COPD program, where almost all of the patients were trained compared to less than half of the patients from the other practices. Last but not least a change from reactive to more proactive and integrative care is necessary to achieve better outcomes in $\operatorname{COPD}(10,18,34)$. A significantly higher percentage of proactive follow up and integrated care in the practice implementing the COPD program was found, which can be explained by the integration of a chest physician, respiratory physiotherapist and a trained practice assistant into the team, facilitating referrals, information transfer and care coordination. 
Taking together all our data, we found that one third of the patients from general health care practices received documented high quality care compared to $95 \%$ of the patients enrolled in the LWWCOPD program. These rather impressive differences warrant deeper reflection and discussion.

The LWWCOPD program(9) is based on the Chronic Care Model (CCM)(23). The CCM identifies the essential elements of a health care system that encourages high-quality chronic disease care. These elements are part of a health system that redesigns care according to a care team approach. It uses clinical information systems, supports self-management, and facilitates decision support. The focus lies on forming productive interactions between informed patients who take an active part in their care and providers with resources and expertise. The practice with the COPD program used some of these elements to improve chronic care delivery. A COPD care team ( lung physician, respiratory physiotherapist and trained practice assistants) dedicated to guideline based, proactive,coordinated care, supported self-management, offered regular follow up calls to patients and ensured an information transfer between the health care deliverers and the patient.

\section{Implications for practice, policy and research}

$21^{\text {st }}$ century practices should incorporate evidence based processes of care.

It is not enough to create guidelines but recommendations have to be incorporated into daily practice. PMs are a postulated tool to help improve health-care quality(21). In the United Kingdom, the National Institute for Health and Clinical Excellence (NICE) guideline implementation strategies use financial and regulatory incentives, including pay-forperformance(35). However, concerns in linking financial incentives to performance exist. It is argued that performance measures are poor predictors of quality and that rewarding quality improvement actions could make more sense than spending resources on measures(36). PMs alone will not improve care unless the results of those measures are linked to efforts to diagnose and eliminate core causes of poor quality and point the way to integrating and coordinating care(37). Some of the most established causes for poor quality are a lack of resources to transform practices and implement quality improving health care delivery concepts like the CCM and the patient centered medical home $(\mathrm{PCMH})(23,34)$.

A central cornerstone for better quality will be value-based reimbursement, rewarding those who contribute to high-quality, cost-effective care across the continuum, regardless of specialty or venue.

\section{Conclusion}

Identifying and bridging performance gaps is central to health care quality.COPD represents an important target condition in which to implement measures to improve care. 


\section{Authors contributions}

CK: data collection and analysis, manuscript writing critical revision and final approval of themanuscript.

SM: conception and design, critical revision and final approval of the manuscript.

$\mathrm{SH}$ : data analysis, critical revision and final approval of the manuscript.

$\mathrm{KD}$ : conception, critical revision and final approval of the manuscript

OS: statistics and analysis, critical revision and final approval of the manuscript

TR: conception and design, financial support, critical revision and final approval of the manuscript.

CS: conception and design, financial support, data collection and analysis, manuscript writing and final approval of the manuscript.

All authors read and approved the final manuscript.

\section{Acknowledgements}

We are grateful to all the participating practice teams. Niklaus Brändli, Oskar Denzler, Markus Frey, Walter Schweizer, Alfred Staehelin-Wey, Praxisgemeinschaft Bruno Maggi,

Daniel Oertle-Meyer, Praxisgemeinschaft Affoltern (Beat Coradi, Martin Schütz), Praxisgemeinschaft Altstetten (René Christen, Sergio Dallafior, Peter Simic, Adrian Glarner), Medix-Gruppenpraxis (Felix Huber,Claudia Steurer-Stey) Gemeinschaftspraxis am Meierhofplatz, (Renate Albrecht, Peter Christen, Marco Zoller), Dorfpraxis Ottenbach, (Eveline Breidenstein, Erich Villiger), Gruppenpraxis Schlossberg (Urs Aemissegger, Akiko Krähenmann, Fiona Fröhlich, Regula Rutz). Sanacare Gruppenpraxis in Winterthur and Zurich Wiedikon.

A special thank belongs to the Department of Health of the Canton of Zurich for the support and funding of this project.

We also like to thank Sibylle Kohler, MD for revision of the English as a native speaker. 


\section{References}

1. Bridevaux PO, Probst-Hensch NM, Schindler C, Curjuric I, Felber Dietrich D, Braendli $O$, et al. Prevalence of airflow obstruction in smokers and never-smokers in Switzerland. The European respiratory journal. 2010 Dec;36(6):1259-69. PubMed PMID: 20413537.

2. Buist AS, McBurnie MA, Vollmer WM, Gillespie S, Burney P, Mannino DM, et al. International variation in the prevalence of COPD (the BOLD Study): a population-based prevalence study. Lancet. 2007 Sep 1;370(9589):741-50. PubMed PMID: 17765523.

3. Anthonisen NR, Connett JE, Kiley JP, Altose MD, Bailey WC, Buist AS, et al. Effects of smoking intervention and the use of an inhaled anticholinergic bronchodilator on the rate of decline of FEV1. The Lung Health Study. JAMA. 1994 Nov 16;272(19):1497-505. PubMed PMID: 7966841. Epub 1994/11/16. eng.

4. Murray CJ, Lopez AD. Alternative projections of mortality and disability by cause 1990-2020: Global Burden of Disease Study. Lancet. 1997 May 24;349(9064):1498-504. PubMed PMID: 9167458.

5. Russi EW, Karrer W, Brutsche M, Eich C, Fitting JW, Frey M, et al. Diagnosis and management of chronic obstructive pulmonary disease: the Swiss guidelines. Official guidelines of the Swiss Respiratory Society. Respiration; international review of thoracic diseases. 2013;85(2):160-74. PubMed PMID: 23406723.

6. Jochmann A, Neubauer F, Miedinger D, Schafroth S, Tamm M, Leuppi JD. General practitioner's adherence to the COPD GOLD guidelines: baseline data of the Swiss COPD Cohort Study. Swiss Med Wkly. 2010 Apr. PubMed PMID: 20407960. ENG.

7. Clinical Practice Guideline Treating Tobacco Use and Dependence 2008 Update Panel La, and Staff. A clinical practice guideline for treating tobacco use and dependence: 2008 update. A U.S. Public Health Service report. Am J Prev Med. 2008 Aug;35(2):158-76. PubMed PMID: 18617085. eng.

8. Steurer-Stey C, Dallalana K, Jungi M, Rosemann T. Management of chronic obstructive pulmonary disease in Swiss primary care: room for improvement. Quality in primary care. 2012;20(5):365-73. PubMed PMID: 23114004.

9. Bourbeau J, Julien M, Maltais F, Rouleau M, Beaupre A, Begin R, et al. Reduction of hospital utilization in patients with chronic obstructive pulmonary disease: a disease-specific self-management intervention. Archives of internal medicine. 2003 Mar 10;163(5):585-91. PubMed PMID: 12622605.

10. Chavannes NH, Grijsen M, van den Akker M, Schepers H, Nijdam M, Tiep B, et al. Integrated disease management improves one-year quality of life in primary care COPD patients: a controlled clinical trial. Primary care respiratory journal : journal of the General Practice Airways Group. 2009 Sep;18(3):171-6. PubMed PMID: 19142557.

11. Suissa $S$, Dell'Aniello $S$, Ernst $P$. Long-term natural history of chronic obstructive pulmonary disease: severe exacerbations and mortality. Thorax. 2012 Nov;67(11):957-63. PubMed PMID: 22684094. Pubmed Central PMCID: 3505864.

12. From the Global Strategy for the Diagnosis, Management and Prevention of COPD, Global Initiative for Chronic Obstructive Lung Disease (GOLD) 2015. Available from:

http://www.goldcopd.org/.

13. Bourbeau J, Sebaldt RJ, Day A, Bouchard J, Kaplan A, Hernandez P, et al. Practice patterns in the management of chronic obstructive pulmonary disease in primary practice: the CAGE study. Can Respir J. 2008 Jan-Feb;15(1):13-9. PubMed PMID: 18292848.

Pubmed Central PMCID: 2677850. Epub 2008/02/23. eng.

14. Ulrik CS, Sorensen TB, Hojmark TB, Olsen KR, Vedsted P. Adherence to COPD guidelines in general practice: impact of an educational programme delivered on location in Danish general practices. Primary care respiratory journal : journal of the General Practice Airways Group. 2013 Mar;22(1):23-8. PubMed PMID: 23070473.

15. Glaab T, Vogelmeier C, Hellmann A, Buhl R. Guideline-based survey of outpatient COPD management by pulmonary specialists in Germany. Int J Chron Obstruct Pulmon Dis. 2012;7:101-8. PubMed PMID: 22371651. Pubmed Central PMCID: 3282602. 
16. Horak BJ, Welton W, Shortell S. Crossing the quality chasm: implications for health services administration education. The Journal of health administration education. 2004 Winter;21(1):15-38. PubMed PMID: 15129898.

17. Wagner EH. Chronic disease management: what will it take to improve care for chronic illness? Effective clinical practice : ECP. 1998 Aug-Sep;1(1):2-4. PubMed PMID: 10345255.

18. Fromer L. Implementing chronic care for COPD: planned visits, care coordination, and patient empowerment for improved outcomes. International journal of chronic obstructive pulmonary disease. 2011;6:605-14. PubMed PMID: 22162647. Pubmed Central PMCID: 3232168.

19. Organisation WH. The World Health Report 2008 - primary Health Care (Now more than ever). Available from: http://www.who.int/whr/2008/en/index.html.

20. OECD. Health at a Glance: Asia/Pacific 2010: OECD; 2010. Available from: http://www.oecd-ilibrary.org/social-issues-migration-health/health-at-a-glance-asia-pacific$20109789264096202-e n$.

21. Heffner JE, Mularski RA, Calverley PM. COPD performance measures: missing opportunities for improving care. Chest. 2010 May;137(5):1181-9. PubMed PMID: 20348199. eng.

22. Steurer-Stey C, Markun S, Lana KD, Frei A, Held U, Wensing M, et al. The improving care in chronic obstructive lung disease study: CAROL improving processes of care and quality of life of COPD patients in primary care: study protocol for a randomized controlled trial. Trials. 2014;15:96. PubMed PMID: 24670200. Pubmed Central PMCID: PMC3986912. eng.

23. Wagner EH, Austin BT, Von Korff M. Organizing care for patients with chronic illness. The Milbank quarterly. 1996;74(4):511-44. PubMed PMID: 8941260.

24. Improving Chronic Illness Care (ICIC). Available from:

http://www.improvingchroniccare.org/.

25. Living well with COPD. Available from: http://www.livingwellwithcopd.com/.

26. Bourbeau J, Nault D. Self-management strategies in chronic obstructive pulmonary disease. Clin Chest Med. 2007 Sep;28(3):617-28, vii. PubMed PMID: 17720048. Epub 2007/08/28. eng.

27. Wu J, Sin DD. Improved patient outcome with smoking cessation: when is it too late? International journal of chronic obstructive pulmonary disease. 2011;6:259-67. PubMed PMID: 21814462. Epub 2011/08/05. eng.

28. Stead LF, Bergson G, Lancaster T. Physician advice for smoking cessation. Cochrane Database Syst Rev. 2008 (2):CD000165. PubMed PMID: 18425860. eng. 29. Poole PJ, Chacko E, Wood-Baker RW, Cates CJ. Influenza vaccine for patients with chronic obstructive pulmonary disease. Cochrane Database Syst Rev. 2006 (1):CD002733. PubMed PMID: 16437444. Epub 2006/01/27. eng.

30. Szilagyi PG, Bordley C, Vann JC, Chelminski A, Kraus RM, Margolis PA, et al. Effect of patient reminder/recall interventions on immunization rates: A review. JAMA. 2000 Oct;284(14):1820-7. PubMed PMID: 11025835. eng.

31. Puhan MA, Gimeno-Santos E, Scharplatz M, Troosters T, Walters EH, Steurer J. Pulmonary rehabilitation following exacerbations of chronic obstructive pulmonary disease. The Cochrane database of systematic reviews. 2011 (10):CD005305. PubMed PMID: 21975749.

32. FitzGerald JM. Targeting lung attacks. Thorax. 2011 May;66(5):365-6. PubMed PMID: 21398372. eng.

33. Johnston KN, Young M, Grimmer KA, Antic R, Frith PA. Barriers to, and facilitators for, referral to pulmonary rehabilitation in COPD patients from the perspective of Australian general practitioners: a qualitative study. Primary care respiratory journal : journal of the General Practice Airways Group. 2013 Sep;22(3):319-24. PubMed PMID: 23797679.

34. Rittenhouse DR, Shortell SM. The patient-centered medical home: will it stand the test of health reform? JAMA : the journal of the American Medical Association. 2009 May 20;301(19):2038-40. PubMed PMID: 19454643. 
35. Doran T, Fullwood C, Gravelle H, Reeves D, Kontopantelis E, Hiroeh U, et al. Pay-forperformance programs in family practices in the United Kingdom. N Engl J Med. 2006 Jul;355(4):375-84. PubMed PMID: 16870916. eng.

36. Werner RM, McNutt R. A new strategy to improve quality: rewarding actions rather than measures. JAMA : the journal of the American Medical Association. $2009 \mathrm{Apr}$ 1;301(13):1375-7. PubMed PMID: 19336714.

37. Downing A, Rudge G, Cheng Y, Tu YK, Keen J, Gilthorpe MS. Do the UK government's new Quality and Outcomes Framework (QOF) scores adequately measure primary care performance? A cross-sectional survey of routine healthcare data. BMC health services research. 2007;7:166. PubMed PMID: 17941984. Pubmed Central PMCID: 2117011. 
Figure 1: legend

Comparison of documented COPD performance measures between primary care practices without a COPD program and the practice running the "Living well with COPD" program 
Table 1: Characteristics of the participating practices

\begin{tabular}{|c|c|c|c|c|c|}
\hline $\begin{array}{l}\text { Practices } \\
\text { characteristics by } \\
\text { regions }\end{array}$ & $\begin{array}{l}\text { Total } \\
(n=14)\end{array}$ & $\begin{array}{l}\text { Total - } \\
\text { practice } \\
\text { with } \\
\text { COPD } \\
\text { program } \\
(B) \\
(n=13)\end{array}$ & $\begin{array}{l}\text { Winterthur } \\
(\mathrm{n}=5)\end{array}$ & $\begin{array}{l}\text { Zurich - } \\
\text { B (n=8) }\end{array}$ & $\begin{array}{l}\text { Zurich practice } \\
\text { with COPD } \\
\text { program (B) } \\
(\mathrm{n}=1)\end{array}$ \\
\hline $\begin{array}{l}\text { No. of patients in } \\
\text { single practices, } n \\
\text { (\%) }\end{array}$ & $20(17)$ & $20(21)$ & $10(27)$ & $10(17)$ & $0(0)$ \\
\hline $\begin{array}{l}\text { No. of patients in } \\
\text { group practices, } n \\
\text { (\%) }\end{array}$ & $95(83)$ & $75(79)$ & $27(73)$ & $48(83)$ & $20(100)$ \\
\hline $\begin{array}{l}\text { Total No. of } \\
\text { patients, } n(\%)\end{array}$ & $115(100)$ & $95(83)$ & $37(32)$ & $58(50)$ & $20(17)$ \\
\hline $\begin{array}{l}\text { No. of computer } \\
\text { based medical } \\
\text { records, } \mathrm{n}(\%)\end{array}$ & $91(79)$ & $71(75)$ & $31(84)$ & $40(69)$ & $20(100)$ \\
\hline $\begin{array}{l}\text { No. of paper based } \\
\text { medical records, } n \\
\text { (\%) }\end{array}$ & $24(21)$ & $24(25)$ & $6(16)$ & $18(31)$ & $0(0)$ \\
\hline
\end{tabular}


Table 2: Patient characteristics (\% depend on the amount $(n)$ of documented characteristics)

\begin{tabular}{|c|c|c|c|c|c|}
\hline $\begin{array}{l}\text { Patient characteristics } \\
\text { Due to missing data } n \text { is in several } \\
\text { categories lower than indicated here. } \\
\text { The percentages correspond to the } \\
\text { effective } n \text {. }\end{array}$ & $\begin{array}{l}\text { Total } \\
(\mathrm{n}=115)\end{array}$ & $\begin{array}{l}\text { Total - B } \\
(\mathbf{n}=95)\end{array}$ & $\begin{array}{l}\text { Winterthur } \\
(\mathbf{n}=\mathbf{3 7})\end{array}$ & $\begin{array}{l}\text { Zurich }- \text { B } \\
(\mathbf{n}=58)\end{array}$ & $B(n=20)$ \\
\hline $\begin{array}{l}\text { Age, years, mean (range: Min } 44 y \text {, } \\
\text { Max } 93 \text { y) }\end{array}$ & 68.25 & 68.74 & 64.25 & 72.25 & 68.70 \\
\hline Male, n (\%) & $66(57)$ & $58(61)$ & $21(57)$ & $37(64)$ & $8(40)$ \\
\hline $\begin{array}{l}\text { BMI (kg/m2), (range: Min 17kg/m2, } \\
\text { Max 43kg/m2) }\end{array}$ & 27 & 27 & 27 & 27 & 26 \\
\hline Current smokers, n (\%) & $50(46)$ & $37(41)$ & $17(52)$ & $20(35)$ & $13(68)^{*}$ \\
\hline $\begin{array}{l}\text { Pack Years, mean (range: 22- } \\
\text { 150years) }\end{array}$ & 56 & 57 & 50 & 62 & 47 \\
\hline$\geq 1$ Comorbidities $^{\circ}$, n (\%) & $84(73)$ & $73(76)$ & $28(76)$ & $45(78)$ & $11(55)$ \\
\hline Diabetes & $17(15)$ & $17(18)$ & $6(16)$ & $11(19)$ & $0(0)$ \\
\hline Hypertension & $65(57)$ & $57(60)$ & $21(57)$ & $36(62)$ & $8(40)$ \\
\hline Coronary artery disease & $32(28)$ & $28(29)$ & $7(19)$ & $21(36)$ & $4(20)$ \\
\hline Heart failure & $10(9)$ & $10(11)$ & $3(8)$ & $7(12)$ & $0(0)$ \\
\hline Depression & $27(23)$ & $23(24)$ & $10(27)$ & $13(22)$ & $4(20)$ \\
\hline Spirometry at COPD onset, n (\%) & $72(59)$ & $61(57)$ & $23(62)$ & $38(66)$ & $11(63)$ \\
\hline GOLD at COPD onset, $\mathrm{n}(\%)$ & $80(70)$ & $68(72)$ & $24(65)$ & $44(76)$ & $12(60)$ \\
\hline GOLD I at COPD onset, $\mathrm{n}(\%)$ & $9(11)$ & $9(13)$ & $3(13)$ & $6(14)$ & $0(0)$ \\
\hline GOLD II at COPD onset, $\mathrm{n}(\%)$ & $51(64)$ & $41(60)$ & $14(58)$ & $27(61)$ & $10(83)$ \\
\hline GOLD III at COPD onset, $\mathrm{n}(\%)$ & $17(21)$ & $16(24)$ & $7(29)$ & $9(20)$ & $1(8)$ \\
\hline GOLD IV at COPD onset, $\mathrm{n}(\%)$ & $3(4)$ & $2(3)$ & $0(0)$ & $2(5)$ & $1(5)$ \\
\hline Spirometry in 2012, $\mathrm{n}(\%)$ & $67(58)$ & $48(51)$ & $19(51)$ & $29(50)$ & $19(95)^{* *}$ \\
\hline GOLD in $2012, \mathrm{n}(\%)$ & $87(76)$ & $68(72)$ & $24(65)$ & $44(76)$ & $19(95)$ \\
\hline GOLD I in 2012, n (\%) & $7(8)$ & $6(9)$ & $3(13)$ & $3(7)$ & $1(5)$ \\
\hline GOLD II in $2012, \mathrm{n}(\%)$ & $44(51)$ & $34(50)$ & $12(50)$ & $22(50)$ & $10(53)$ \\
\hline GOLD III in 2012, n (\%) & $28(23)$ & $23(34)$ & $9(38)$ & $14(32)$ & $5(26)$ \\
\hline GOLD IV in $2012, \mathrm{n}(\%)$ & $8(9)$ & $5(7)$ & $0(0)$ & $5(11)$ & $3(16)$ \\
\hline $\begin{array}{l}\text { Years since COPD onset, mean range } \\
\text { (Min 1y, Max 16y) }\end{array}$ & 5.28 & 5.69 & 4.32 & $6.54 \#$ & $2.69^{* *}$ \\
\hline Cough, n (\%) & $62(54)$ & $54(57)$ & $18(49)$ & $36(62)$ & $8(40)$ \\
\hline Sputum production, n (\%) & $40(35)$ & $32(34)$ & $9(24)$ & $23(40)$ & $8(40)$ \\
\hline Dyspnoe, n (\%) & $78(68)$ & $62(65)$ & $22(59)$ & $40(70)$ & $16(80)$ \\
\hline $\begin{array}{l}\text { Severity of dyspnea (MRC scale): } 0-2, n \\
(\%)\end{array}$ & $22(76)$ & $8(67)$ & $3(75)$ & $5(63)$ & $14(82)$ \\
\hline $\begin{array}{l}\text { Severity of dyspnea (MRC scale): }>2, n \\
(\%)\end{array}$ & $7(24)$ & $4(33)$ & $1(25)$ & $3(38)$ & $3(15)$ \\
\hline $\begin{array}{l}\text { Exacerbations/year, mean (range: 0-4 } \\
\text { Exacerbations) }\end{array}$ & 1.39 & 1.42 & 1.28 & 1.50 & 1.27 \\
\hline$\geq 2$ Exacerbations/year, n (\%) & $16(16)$ & $13(26)$ & $4(22)$ & $9(28)$ & $3(27)$ \\
\hline $\begin{array}{l}\text { Hospitalisations/year, mean (range: } 0 \\
\text {-3 Hospitalisations) }\end{array}$ & 1.24 & 1.25 & 1.00 & 1.33 & 1.20 \\
\hline
\end{tabular}


${ }^{*} \mathrm{p}=0.030 ;{ }^{* *} \mathrm{p}<0.01$ compared to (Total-B); $\# \mathrm{p}=0.012$ compared to Winterthur
The comorbidities heart failure and diabetes were not documented in the twenty patients from practice B, therefore
statistical comparison can't be done between B and the other practices. 
Table 3: Documentation of non-pharmacological measures (\% depend on the amount (n) of documented characteristics)

\begin{tabular}{|c|c|c|c|c|c|}
\hline $\begin{array}{l}\text { Documentation of } \\
\text { performance measures }\end{array}$ & $\begin{array}{l}\text { Total } \\
(n=115)\end{array}$ & $\begin{array}{l}\text { Total - } \\
\text { B }(n=95)\end{array}$ & $\begin{array}{l}\text { Winterthur } \\
(n=37)\end{array}$ & $\begin{array}{l}\text { Zurich - } \\
\text { B }(n=58)\end{array}$ & $\begin{array}{l}B \\
(n=20)\end{array}$ \\
\hline $\begin{array}{l}\text { Assessment of smoking status, } \\
\text { n (\%) }\end{array}$ & $109(95)$ & $90(95)$ & $33(89)$ & $57(98)$ & $19(95)$ \\
\hline $\begin{array}{l}\text { Smoking cessation advice, } n \\
(\%) \\
(\mathrm{n}=\mathbf{5 0} \text { active smokers) }\end{array}$ & $37(74)$ & $24(65)$ & $12(71)$ & $12(60)$ & $\begin{array}{r}13 \\
(100)^{*}\end{array}$ \\
\hline $\begin{array}{l}\text { Smoking cessation } \\
\text { intervention, } n(\%)(n=50 \\
\text { active smokers })\end{array}$ & $26(52)$ & $14(38)$ & $9(53)$ & $5(25)$ & $\begin{array}{r}12(92) \\
* *\end{array}$ \\
\hline $\begin{array}{l}\text { Annual influenza vaccination, } \\
\text { n (\%) }\end{array}$ & $56(49)$ & $47(49)$ & $16(43)$ & $31(53)$ & $9(45)$ \\
\hline $\begin{array}{l}\text { Assessment of physical } \\
\text { activity, n (\%) }\end{array}$ & $69(60)$ & $50(52)$ & $20(54)$ & $30(52)$ & $\begin{array}{r}19(95) \\
* *\end{array}$ \\
\hline $\begin{array}{l}\text { Advice for physical activity, } n \\
(\%)\end{array}$ & $61(53)$ & $42(44)$ & $17(46)$ & $25(43)$ & $\begin{array}{r}19(95) \\
* *\end{array}$ \\
\hline $\begin{array}{l}\text { Instruction in correct } \\
\text { inhalation technique, } n(\%)\end{array}$ & $65(57)$ & $46(48)$ & $13(35)$ & $33(57) \#$ & $\begin{array}{r}19(95) \\
* *\end{array}$ \\
\hline $\begin{array}{l}\text { Information about the } \\
\text { therapy, n (\%) }\end{array}$ & $62(54)$ & $43(45)$ & $12(32)$ & $31(53) \#$ & $\begin{array}{r}19(95) \\
* *\end{array}$ \\
\hline $\begin{array}{l}\text { Information about disease, } n \\
(\%)\end{array}$ & $64(56)$ & $45(47)$ & $15(41)$ & $30(51)$ & $19(95)$ \\
\hline $\begin{array}{l}\text { Instruction in exacerbation } \\
\text { management with a written } \\
\text { action plan, } n(\%)\end{array}$ & $28(24)$ & $8(8)$ & $3(8)$ & $5(9)$ & $\begin{array}{r}20 \\
(100) \\
* *\end{array}$ \\
\hline $\begin{array}{l}\text { Use of a written action plan, } n \\
(\%)\end{array}$ & $18(16)$ & $2(2)$ & $1(3)$ & $1(2)$ & $\begin{array}{r}16(80) \\
* *\end{array}$ \\
\hline $\begin{array}{l}\text { Advice of pulmonary } \\
\text { rehabilitation, } n(\%)\end{array}$ & $31(27)$ & $11(12)$ & $4(11)$ & $7(12)$ & $\begin{array}{r}20 \\
(100) \\
* *\end{array}$ \\
\hline $\begin{array}{l}\text { Referral to a pulmonary } \\
\text { rehabilitation, } n(\%)\end{array}$ & $28(24)$ & $11(12)$ & $5(14)$ & $6(10)$ & $\begin{array}{r}17(85) \\
* *\end{array}$ \\
\hline $\begin{array}{l}\text { Integrated and coordinated } \\
\text { care, } n(\%)\end{array}$ & $69(60)$ & $50(53)$ & $16(43)$ & $34(59)$ & $\begin{array}{r}19(95) \\
* *\end{array}$ \\
\hline Proactive care, n (\%) & $59(51)$ & $40(42)$ & $12(32)$ & $28(48)$ & $\begin{array}{r}19(95) \\
* *\end{array}$ \\
\hline
\end{tabular}




\begin{tabular}{|llllll|}
\hline Drug & $\begin{array}{l}\text { Total } \\
(\mathbf{n = 1 1 5})\end{array}$ & $\begin{array}{l}\text { Total - B } \\
(\mathbf{n = 9 5})\end{array}$ & $\begin{array}{l}\text { Winterthur } \\
(\mathbf{n = 3 7 )}\end{array}$ & $\begin{array}{l}\text { Zurich - B } \\
(\mathbf{n = 5 8}=\end{array}$ & $\begin{array}{l}\text { B } \\
(\mathbf{n}=\mathbf{2 0})\end{array}$ \\
\hline ICS/LABA, n (\%) & $70(61)$ & $56(59)$ & $16(43)$ & $40(69)^{*}$ & $14(70)$ \\
\hline ICS, n (\%) & $10(9)$ & $9(9)$ & $4(11)$ & $5(9)$ & $1(5)$ \\
\hline LAMA, n (\%) & $81(70)$ & $65(68)$ & $31(84)$ & $34(59)^{* *}$ & $16(80)$ \\
\hline LABA, n (\%) & $25(22)$ & $21(22)$ & $12(32)$ & $9(16)$ & $4(20)$ \\
\hline SABA, n (\%) & $41(36)$ & $31(33)$ & $16(43)$ & $15(26)$ & $10(50)$ \\
\hline $\begin{array}{l}\text { SABA/SAMA, n } \\
\text { (\%) }\end{array}$ & $6(5)$ & $6(6)$ & $0(0)$ & $6(10)$ & $0(0)$ \\
\hline *p=0.013; **p=0.010 compared to Winterthur & & & \\
\hline
\end{tabular}

Abbreviations:

LABA = Long-acting beta2-agonist; ICS = Inhaled corticosteroids

ICS/LABA = Combination of a long-acting beta2-agonist and an inhaled corticosteroid in a single inhaler; LAMA = Long-acting antimuscarine antagonist; SABA = Short-acting beta2agonist

SAMA = Short-acting antimuscarine antagonist; SABA/SAMA = Combination of a shortacting beta2-agonist and a short-acting antimuscarine antagonist in a single inhaler 